\title{
Analisis Faktor-Faktor Penghambat Pekerjaan Peningkatan Jalan Lingkungan
}

\author{
Trissiyana \\ Program Studi Teknik Sipil Fakultas Teknik Universitas Antakusuma
}

\begin{abstract}
ABSTRAK. Jalan lingkungan merupakan jalan umum yang berfungsi melayani angkutan lingkungan dengan ciri perjalanan jarak dekat, dan kecepatan rata - rata rendah. Jalan lingkungan yang ada di pemukiman sebagian besar berupa gang yang memiliki dimensi yang beragam. Jalan lingkungan memiliki peranan penting dalam aktivitas masyarakat, karena merupakan jalan yang setiap hari digunakan masyarakat untuk beraktivitas. Adapun tujuan dari Penelitian ini antara lain untuk Mengetahui factor-faktor umum yang sering menghambat penyelesaian pekerjaan, serta peringkat (rangking) dari faktor-faktor tersebut. Penelitian dilakukan pada pekerjaan peningkatan jalan lingkungan (cor beton) di Kabupaten Kotawaringin Baratb 2017. Metode penelitian yang diterapkan untuk tugas akhir ini menggunakan salah satu jenis metode penelitian deskriptif yaitu penelitian survei. Penelitian yang dilakukan berupa survei dengan cara menjaring pendapat atau persepsi, pengalaman, dan sikap responden mengenai waktu efekti pelaksanaan kegiatan peningkatan jalan lingkungan. Berdasarkan hasil penelitian dapat disimpulkan sebagai berikut yaitu lima (5) Faktor yang paling berpengaruh terhadap keterlambatan proyek adalah a. Gangguan Cuaca, dengan nilai mean 2,56 dan masuk kategori sangat berpengaruh. b. Ketersediaan modal awal pekerjaan, dengan nilai mean 2,43 dengan kategori berpengaruh. c. Ketersediaan tenaga kerja, dengan nilai mean 2,20 dengan kategori berpengaruh. d. Keterlambatan persetujuan hasil tes uji laboratorium (Mutu Beton), dengan nilai mean 2,16 dengan kategori berpengaruh. e. Keamanan lingkungan, dengan nilai mean 2,12 dengan kategori berpengaruh.
\end{abstract}

Kata kunci: faktor penghambat, jalan lingkungan

\section{PENDAHULUAN}

Di Kabupaten Kotawaringin Barat penjadwalan waktu pelaksanaan pekerjaan cenderung sama pada sebagian besar kegiatan proyek pemerintah. Penentuan waktu pelaksanaan kegiatan terkesan tidak mengacu pada bobot pekerjaan, pada pelaksanaan pekerjaan yang memiliki bobot pekerjaan yang tergolong ringan mendapat jatah waktu pelaksanaan pekerjaan yang sama dengan pelaksanaan pekerjaan yang terdiri dari pekerjaan - pekerjaan yang tergolong rumit. Jalan lingkungan merupakan jalan umum yang berfungsi melayani angkutan lingkungan dengan ciri perjalanan jarak dekat, dan kecepatan rata - rata rendah. Jalan lingkungan yang ada di pemukiman sebagian besar berupa gang yang memiliki dimensi yang beragam. Jalan lingkungan memiliki peranan penting dalam aktivitas masyarakat, karena merupakan jalan yang setiap hari digunakan masyarakat untuk beraktivitas.

Karena pentingnya jalan lingkungan bagi masyarakat, pemerintah Kabupaten Kotawaringin Barat mengadakan kegiatan / proyek peningkatan jalan lingkungan hampir setiap tahun. Adapun tujuan dari Penelitian ini untuk mengetahui faktor - faktor umum yang 
sering menghambat penyelesaian pekerjaan, serta peringkat (rangking) dari faktor-faktor tersebut.

\section{METODE PENELITIAN}

\section{Lokasi Penelitian}

Penelitian dilakukan pada pekerjaan peningkatan jalan lingkungan (cor beton) di Kabupaten Kotawaringin Barat.

\section{Pengumpulan dan Analisis Data}

Pengumpulan data dilakukan dengan mengumpulkan dua jenis sumber data, yaitu data - data primer, berupa data - data yang dikumpulkan dari studi kasus pengamatan lapangan secara informal, yaitu menyebarkan kuesioner ke responden. Data - data sekunder berupa data - data yang diperoleh dari studi literatur dengan berbagai buku referensi, dokumen proyek, dan jurnal.

Metode penelitian yang diterapkan untuk penelitian ini menggunakan salah satu jenis metode penelitian deskriptif yaitu penelitian survei. Penelitian survei pada umumnya dilakukan untuk mengambil suatu generalisasi dari pengamatan yang tidak mendalam. Penelitian yang dilakukan berupa survei dengan cara menjaring pendapat atau persepsi, pengalaman, dan sikap responden mengenai faktor-faktor penghambat pelaksanaan kegiatan peningkatan jalan lingkungan.

\section{Responden Penelitian}

Responden penelitian dari studi kasus yang dilakukan adalah pihak - pihak yang menangani pekerjaan peningkatan jalan lingkungan (cor beton) di Kotawaringin Barat, yang terdiri dari pemilik kegiatan, pelaksana kegiatan, serta pengawas kegiatan. Populasi dari penelitian kali ini adalah proyek pekerjaan peningkatan jalan lingkungan yang menggunakan konstruksi cor beton di Kotawaringin Barat. Setelah melakukan pencarian data, didapat jumlah populasi atau jumlah proyek pekerjaan peningkatan jalan lingkungan di Kotawaringin Barat tahun 2017 adalah 50 pekerjaan. didapat :

Sehingga dengan rumus SLOVIN

$$
\mathrm{n}=\frac{50}{1+50(10 \%)^{2}}=33,333
$$

Berdasarkan perhitungan diatas didapat jumlah sampel adalah 33. Pengambilan sampel ini diharapkan dapat memberikan data yang akurat berdasarkan kondisi di lokasi proyek yang diteliti.

Dalam penelitian ini mengambil sampel 33 pekerjaan, dan di setiap pekerjaan tersebut kuisioner akan di berikan kepada pihak pelaksana, konsultan pengawas, serta pengawas dinas PU, sehingga jumlah responden dalam penelitian ini adalah 99 orang. Berikut adalah komposisi responden berdasarkan institusi dan pendidikan terakhir responden.

Tabel 1. Variabel Komposisi berdasarkan Jabatan dan pendidikan

\begin{tabular}{|c|c|c|c|c|c|c|}
\hline \multirow{2}{*}{ No. } & \multirow{2}{*}{$\begin{array}{l}\text { Jabatan } \\
\text { Dalam } \\
\text { Proyek }\end{array}$} & \multicolumn{4}{|c|}{ Pendidikan } & \multirow{2}{*}{$\mathrm{Jlh}$} \\
\hline & & SLTA & D3 & S1 & $\mathrm{S} 2$ & \\
\hline 1 & Kontraktor & 29 & 0 & 4 & 0 & 33 \\
\hline 2 & $\begin{array}{l}\text { Konsultan } \\
\text { Pengawas }\end{array}$ & 4 & 2 & 27 & 0 & 33 \\
\hline 3 & $\begin{array}{l}\text { Pengawas } \\
\text { Dinas PU }\end{array}$ & 18 & 4 & 5 & 6 & 33 \\
\hline & Jumlah & 51 & 6 & 36 & 6 & 99 \\
\hline \multicolumn{2}{|c|}{ Persentase } & 51,52 & 6,06 & 36,36 & 6,06 & 100 \\
\hline
\end{tabular}

Pada tabel dapat dilihat latar belakang pendidikan responden dan jabatan responden dalam proyek/pekerjan. Dari tabel diatas dapat di uraikan sebagai berikut :

1. SLTA

Untuk kategori pendidikan SLTA, jumlah responden mencapai $51,51 \%$ atau sebanyak 51 responden. Jumlah tersebut terbagi dari kontraktor/pelaksana 29 responden, konsultan pengawas 4 responden, serta pengawas dinas PU 18 responden.

2. D3

Untuk kategori pendidikan Diploma 3, hanya terdapat 6 responden atau $6,06 \%$. Jumlah tersebut terbagi dari kontraktor/pelaksana 0 responden, 
konsultan pengawas 2 responden, serta pengawas dinas PU 4 responden.

3. $\mathrm{S} 1$

Untuk kategori pendidikan S1, terdapat 36 responden atau 36,36\%. Jumlah tersebut terbagi dari kontraktor/pelaksana 4 responden, konsultan pengawas 27 responden, serta pengawas dinas PU 5 responden.

Tabel 2. Variabel Komposisi berdasarkan Pekerjaan dan Umur
4. $\mathrm{S} 2$

Untuk kategori pendidikan S2, hanya terdapat 6 responden atau 6,06\%. Jumlah hanya terdiri dari pengawas dinas PU saja, yaitu sebanyak 6 responden.

Berikut adalah komposisi responden berdasarkan pekerjaan dan umur responden.

\begin{tabular}{|c|c|c|c|c|c|c|}
\hline \multirow{2}{*}{ No. } & \multirow{2}{*}{ Pekerjaan/Proyek } & \multicolumn{4}{|c|}{ Umur } & \multirow{2}{*}{ Jumlah } \\
\hline & & $<30$ thn & $30-40$ thn & $41-45$ thn & $>45$ thn & \\
\hline 1. & Kontraktor & 0 & 26 & 7 & 0 & 33 \\
\hline 2. & Konsultan Pengawas & 22 & 10 & 1 & 0 & 33 \\
\hline 3. & Pengawas Dinas PU & 2 & 15 & 4 & 12 & 33 \\
\hline & Jumlah & 24 & 51 & 12 & 12 & 99 \\
\hline & Persentase & 24,24 & 51,52 & 12,12 & 12,12 & 100 \\
\hline
\end{tabular}

Dari tabel diatas dapat di uraikan sebagai berikut :

1. Usia dibawah 30 tahun

Untuk kategori usia dibawah 30 tahun terdapat 24 responden atau $24,24 \%$ dari keseluruhan responden yang ada. Jumlah tersebut terdiri dari pengawas konsultan 22 responden, dan pengawas dinas PU 2 responden.

2. Usia 30 - 40 tahun

Kategori usia dibawah 30-40 tahun menjadi usia responden yang paling dominan, yaitu 51,52\% dari keseluruhan responden yang ada atau 51 responden. Jumlah tersebut terdiri dari pengawas konsultan $10 \quad$ responden, kontraktor/pelaksana 26 responden, dan pengawas dinas PU 15 responden.

3. Usia 41-45 tahun

Untuk kategori usia dibawah 41-45 tahun terdapat 12 responden atau 12,12\% dari keseluruhan responden yang ada. Jumlah tersebut terdiri dari pengawas konsultan 1 responden, kontraktor/pelaksana 7 responden, dan pengawas dinas PU 4 responden.

\section{HASIL DAN PEMBAHASAN}

Berdasarkan pada jumlah mean yang didapat, faktor - faktor keterlambatan proyek tersebut diberi rangking/tingkatan yang menggambarkan besarnya pengaruh dari masing-masing faktor tesebut.

Selanjutnya untuk memberi penilaian pada harga rata-rata dibuat batasan sebagai berikut : harga rata - rata kurang dari 0,50 (tidak berpengaruh), 0,51 - 1,49 (agak berpengaruh), 1,50 - 2,49 (berpengaruh), 2,50 - 3,00 (sangat berpengaruh), sebagaimana terlihat pada tabel dibawah ini.

Tabel 3. Penjelasan arti interval Nilai Mean

\begin{tabular}{ccc}
\hline $\begin{array}{c}\text { Interval } \\
\text { Nilai }\end{array}$ & Arti & Frekuensi \\
\hline$<0,50$ & Tidak berpengaruh & 0 \\
$0,51-1,49$ & Agak berpengaruh & 6 \\
$1,50-2,50$ & Berpengaruh & 18 \\
$2,51-3,00$ & Sangat berpengaruh & 1 \\
\hline & Jumlah & 25 \\
\hline
\end{tabular}


Tabel 4. Rangking Faktor Keterlambatan Proyek

\begin{tabular}{clrc}
\hline No & \multicolumn{1}{c}{ Faktor - faktor yang menyebabkan keterlambatan proyek } & Mean & Rangking \\
\hline 1 & Gangguan Cuaca & 2,56 & 1 \\
2 & Ketersediaan modal awal pekerjaan & 2,43 & 2 \\
3 & Ketersediaan tenaga kerja & 2,20 & 3 \\
4 & Keterlambatan persetujuan hasil tes uji laboratorium (Mutu Beton) & 2,16 & 4 \\
5 & Keamanan lingkungan & 2,12 & 5 \\
6 & Tidak cukupnya Peralatan & 2,10 & 6 \\
7 & Tidak cukupnya material & 2,06 & 7 \\
8 & Lalu lintas masyarakat pada jalan yang dikerjakan & 2,05 & 8 \\
9 & Akses ke lokasi proyek & 2,05 & 8 \\
10 & Kesalahan membaca gambar & 2,04 & 9 \\
11 & Kesalahan dalam perencanaan & 2,03 & 10 \\
12 & Keahlian tenaga kerja & 1,99 & 11 \\
13 & Kerusakan atau kehilangan peralatan & 1,97 & 12 \\
14 & Terjadinya kenaikan harga bahan/material & 1,94 & 13 \\
15 & Perubahan dalam perencanaan & 1,93 & 14 \\
16 & Lokasi proyek & 1,87 & 15 \\
17 & Terjadi kehilangan material dilapangan & 1,86 & 16 \\
18 & Kondisi fisik dilapangan yang berbeda dengan kondisi di perencanaan & 1,81 & 17 \\
19 & Kecelakaan kerja & 1,76 & 18 \\
20 & Permasalahan dengan masyarakat sekitar lokasi pekerjaan & 1,43 & 19 \\
21 & Aksi mogok kerja & 1,37 & 20 \\
22 & Pekerjaan bertepatan bulan puasa dan lebaran & 1,29 & 21 \\
23 & Penggantian tenaga kerja baru & 1,17 & 22 \\
24 & Pembebasan Lahan & 1,05 & 23 \\
25 & Paksaan/tekanan oleh pihak tertentu & 0,91 & 24 \\
\hline & & &
\end{tabular}

Berdasarkan pada tabel diatas didapat bahwa faktor - faktor keterlambatan yang di cantumkan dalam kuesioner memang memiliki pengaruh terhadap pelaksanaan pekerjaan, hal itu dibuktikan dengan tidak adanya pertanyaan yang mendapat nilai dibawah 0,50 .
Untuk pertanyaan yang bernilai 0,51 1,49 , atau dengan arti agak berpengaruh juga mendapatkan prosentase yang cukup kecil yaitu hanya 6 pertanyaan, atau $24 \%$ dari total 25 faktor yang diberikan. Faktor yang termasuk dalam kategori ini adalah sebagai berikut :

Tabel 5. Faktor Dengan Kategori Agak Berpengaruh

\begin{tabular}{clcc}
\hline No & \multicolumn{1}{c}{ Faktor } & Mean & Rangking \\
\hline 1. & Permasalahan dengan masyarakat sekitar lokasi pekerjaan & 1,43 & 19 \\
2. & Aksi mogok kerja & 1,37 & 20 \\
3. & Pekerjaan bertepatan bulan puasa dan lebaran & 1,29 & 21 \\
4. & Penggantian tenaga kerja baru & 1,17 & 22 \\
5. & Pembebasan Lahan & 1,05 & 23 \\
6. & Paksaan/tekanan oleh pihak tertentu & 0,91 & 24 \\
\hline
\end{tabular}


Sedangkan yang masuk kategori berpengaruh adalah sebagai berikut :

Tabel 6. Faktor Dengan Kategori Berpengaruh

\begin{tabular}{clcc}
\hline No. & \multicolumn{1}{c}{ Faktor } & Mean & Rangking \\
\hline 1. & Ketersediaan modal awal pekerjaan & 2,43 & 2 \\
2. & Ketersediaan tenaga kerja & 2,20 & 3 \\
3. & Keterlambatan persetujuan hasil tes uji laboratorium (Mutu Beton) & 2,16 & 4 \\
4. & Keamanan lingkungan & 2,12 & 5 \\
5. & Tidak cukupnya Peralatan & 2,10 & 6 \\
6. & Tidak cukupnya material & 2,06 & 7 \\
7. & Lalu lintas masyarakat pada jalan yang dikerjakan & 2,05 & 8 \\
8. & Akses ke lokasi proyek & 2,05 & 8 \\
9. & Kesalahan membaca gambar & 2,04 & 9 \\
10. & Kesalahan dalam perencanaan & 2,03 & 10 \\
11. & Keahlian tenaga kerja & 1,99 & 11 \\
12. & Kerusakan atau kehilangan peralatan & 1,97 & 12 \\
13. & Terjadinya kenaikan harga bahan/material & 1,94 & 13 \\
14. & Perubahan dalam perencanaan & 1,93 & 14 \\
15. & Lokasi proyek & 1,87 & 15 \\
16. & Terjadi kehilangan material dilapangan & 1,86 & 16 \\
17. & Kondisi fisik dilapangan yang berbeda dengan kondisi di perencanaan & 1,81 & 17 \\
18. & Kecelakaan kerja & 1,76 & 18 \\
\hline
\end{tabular}

Jadi ada 5 (lima) Faktor yang paling berpengaruh terhadap keterlambatan proyek adalah :

1. Gangguan Cuaca, dengan nilai mean 2,56 dan masuk kategori sangat berpengaruh.

2. Ketersediaan modal awal pekerjaan, dengan nilai mean 2,43 dengan kategori berpengaruh.

3. Ketersediaan tenaga kerja, dengan nilai mean 2,20 dengan kategori berpengaruh.

4. Keterlambatan persetujuan hasil tes uji laboratorium (Mutu Beton), dengan nilai mean 2,16 dengan kategori berpengaruh.

5. Keamanan lingkungan, dengan nilai mean 2,12 dengan kategori berpengaruh

Hanya faktor gangguan cuaca yang menempati kategori sangat berpengaruh dengan nilai mean 2,56.

\section{KESIMPULAN}

Berdasarkan hasil penelitian dapat disimpulkan sebagai berikut :

5 (lima) Faktor yang paling berpengaruh terhadap keterlambatan proyek adalah
1. Gangguan Cuaca, dengan nilai mean 2,56 dan masuk kategori sangat berpengaruh.

2. Ketersediaan modal awal pekerjaan, dengan nilai mean 2,43 dengan kategori berpengaruh.

3. Ketersediaan tenaga kerja, dengan nilai mean 2,20 dengan kategori berpengaruh.

4. Keterlambatan persetujuan hasil tes uji laboratorium (Mutu Beton), dengan nilai mean 2,16 dengan kategori berpengaruh.

5. Keamanan lingkungan, dengan nilai mean 2,12 dengan kategori berpengaruh.

\section{SARAN}

Berdasarkan kepada kesimpulan yang diambil pada penelitian kali ini, dapat disarankan sebagai berikut :

1. Bagi pemilik proyek (owner) disarankan agar mengkaji kembali efaktifitas penetapan waktu pelaksanaan pekerjaan (waktu kontrak), agar lebih mempertimbangkan bobot pekerjaan tersebut. 
2. Bagi pelaksana disarankan untuk memperhitungkan dengan benar produktifitas dari pekerjaannya.

3. Bagi semua pihak yang terlibat dalam pekerjaan disarankan agar mempertimbangkan faktor-faktor yang telah diuraikan diatas, untuk meminimalisir kemungkinan terjadinya keterlambatan kerja.

\section{DAFTAR PUSTAKA}

Abdurrahman, M., Nur, A., dkk., 2012. Analisa Pengelolaan Risiko ProyekProyek Pengairan, Makasar, Universitas Hasanuddin

Bulls, 1998, Faktor - Faktor Penyebab Kegagalan Pelaksanaan Proyek, Perancis.

Canada Survey, KPMG., 1997, Kegagalan Pelaksanaan Proyek, Canada.

Dinas PU Daerah Kab. Kobar, 2013, Dokumen Kontrak Pekerjaan, Kabupaten Kotawaringin Barat.

Dipohusodo, I., 1996, Manajemen Proyek Dan Konstruksi Jilid 1, Gramedia Pustaka Utama, Jakarta.

Furqon, 1997, Statistika Terapan Untuk Penelitian, CV. Alfabeta, Bandung.

Handoko, T.H.. 1999, Dasar-Dasar Manajemen Produksi Dan Operasi, Edisi Pertama. Bpfe, Yogyakarta.

Haryanto, 2012, Pendekatan Jenis Dan Metode Penelitian.
Lock, D., 1990, Manajemen Proyek, Berikut Kepres 29/30 Tahun 1984, Edisi Ke 3, Jakarta, Salemba Empat.

Moleong, L. J., 1988, Metodologi Penelitian Kualitatif, Bandung, Pt. Remaja Rosdakarya.

Project Management Institute, 2004, A Guide To The Project Management Body Of Knowledge. 3rd Edition. E-Book. Project Management Institute, USA.

Reksohadipradjo, S., 1997, Manajemen Proyek, Yogyakarta, Bpfe.

Rina A., dkk., 2013, Faktor-Faktor Risiko Keterlambatan Pelaksanaan Pekerjaan Konstruksi di Bidang Sungai Dinas Pengairan Aceh, Aceh, Universitas Syiah Kuala.

Soeharto, I., 2001, Manajemen Proyek : Dari Konseptual Sampai Operasional, Jakarta, Erlangga.

Suyatno, 2010, Analisis Faktor Penyebab Keterlambatan Penyelesaian Proyek Gedung. Tesis, Semarang, Universitas Diponegoro Semarang.

The Standish Group, 1995, Chaos Report, 5 Penyebab Utama Kegagalan Implementasi Proyek. 